\title{
Exploring the Dimensions of Multicultural Education and its Implication in Teaching Learning
}

\author{
Dawa Sherpa \\ Lecturer \\ Central Department of Education \\ Tribhuvan University, Kathmandu, Nepal \\ Email: dawa084@gmail.com
}

\begin{abstract}
This article aims to present the concept and needs of multicultural education in Nepal. This paper is based on extensive review of literature on multicultural education in Nepal. Multicultural education provides equal educational opportunities for all races, nations and groups of different cultures. Cultural values, ethics, norms and practices are focused on multicultural education. It helps to find out the cultural knowledge and skills in the learners and communicate with other ethnic groups. Multicultural curriculum can prepare individuals and groups with diverse backgrounds to live peacefully in a society. Multicultural education promotes the strength and value of cultural diversity. Moreover, it also ensures human rights and respect to one another and the acceptance of alternative life styles of people, and the promotion of social justice.
\end{abstract}

Keywords: Multicultural education, diversity, multicultural dimensions, multicultural needs

\section{Introduction}

Constitutions of Nepal (2015) states that, Nepal is multi-ethnic, multi-lingual, multi-cultural country. In Nepal there are125 castes and ethnic groups speaking 123 languages (Central Bureau of Statistics [CBS], 2011). School is a social institution, that is affected by scientific, cultural, political, social and global changes and it is expected to adapt itself with unavoidable form of our needs (Mostafazaseh, Keshtiaray, \& Ghulizadeh, 2015). According to Wilson, (2008) the term "multicultural" denotes the development of relations between countries and their moving towards a global or at least regional military, the ethnic and cultural differences. Multi-culture incorporates ideas and beliefs of people from many different cultural background and countries. It is co-existence of diverse cultures, where culture includes cultural groups and is manifested in customary behaviors, cultural assumptions and values, patterns of thinking, and communicative styles.

Multicultural education is defined as being meaningful for different lives and different ideas for an educational reform movement, and a process (Salgur \& Gursoy, 2015). Students, regardless of their gender, social class, and ethnic, racial, or cultural characteristics, should have an equal 
opportunity to learn in school (Ibid.). The same authors concluded that the solutions to problems of education in societies having different ethnic groups can be found in multicultural education.

Nepal has the experiences of monoculture education both in school and higher education. Cultural diversity is limitedly recognized and several cultures are under the shadow. Curriculum practices are mono-cultural. Most teachers are not familiar with inclusive pedagogy. Thus ethnic culture, language, religions are hardly integrated in educational practices. Such mono-cultural education could not address the diversified cultures of Nepal. In this context this paper aims to explore the concept and needs of multicultural education in Nepal.

\section{Methods}

This paper is based on extensive review of literature on multicultural education. For this I reviewed different international and national journals, books and reports. I also used the information collected from library and extensive internet searches. Particularly, I have searched peer reviewed articles available in JSTOR and ERIC database. The content, fact and information found in the literature were analyzed and interpreted critically.

\section{Discussions}

\section{Concept and process of Multicultural Education}

The multicultural concept is derived from varieties of cultures in which indigenous thoughts are imbedded for the creations of new knowledge. With this the dignity of each and every individuals are equally valuable and appreciated within the culture. This also focuses on the advocacy of humanism across the varieties of cultural norms and values. Multicultural education is very broad diverse and rooted in context and situations (Mostafazaseh, Keshtiaray, \& Ghulizadeh, 2015). Multicultural education is a humanistic concept, which is based on identity, diversity, human rights, social justice and the possibility to select the different lifestyles of each person. Multicultural approach is to pursuing engagement, understanding and cultural exchange between and among cultures, so that different cultures can co-exist peacefully and with less stress (Tiedt, \& Tiedt, 1995).Rather than becoming confused in debates over which definition of multiculturalism is correct, developmental educators and the students we teach will be best served by drawing together key strengths of the dominant approaches (Patrick, Rashne, Walter.\& David 2004). Multicultural Education, in its current definition applies to all policies and issues that schools should operate to improve educational outcomes of all students which have different nationality, class, religion, and gender and gifted children. In other words, the concept of multicultural education is a concept in which all students regardless group of which they belong, shall be entitled to equality of educational opportunity in school (Mostafazaseh, Keshtiaray, \& Ghulizadeh, 2015).

"Multiculturalism takes consideration on race, ethnic structure, language, gender, age, disability, social class, education, religious orientation and dimensions of other cultures. In societies that are welcoming differences the cultural basis and academic success are provided by education" (Salgur, \& Gursoy, 2015)

In multicultural education, various instructional techniques such as lecture, cooperative learning, dialogue, individual work, student teaching is applied. Content must be complete and accurate, acknowledging the contributions and perspectives of all groups and weave the contents about 
under-represented groups of color, women, lesbian, gay, and bisexual people, people with disabilities, etc. seamlessly with that about traditionally over-represented groups. Teaching and learning materials must be diverse and critically examined for bias. Variety of instructional materials, newspapers, videos/movies, games, workbooks and learning content must be presented from a variety of perspectives in order to be fit not only that of majority groups but also minority and disadvantaged groups of learners. The perspectives and experiences of the different groups of learning experience. Encourage students to ask critical questions about all information they receive from you and curricular materials, and model this type of critical thinking for them.

According to Banks (1999) in multicultural schools,

The teachers and school administrators have high expectations for all students and positive attitudes toward them. They also respond to them in positive and caring ways. The formal curriculum reflects the experiences, cultures, and perspectives of a range of cultural and ethnic groups as well as of both genders. The teaching styles used by the teachers match the learning, cultural, and motivational styles of the students (p.17).

The goal of multicultural education is considered to provide equal educational opportunities for all races, nations and groups of different cultures (Banks \& Banks, 1995). It helps to interact and communicate with other ethnic groups of population. Multicultural curriculum, can prepare individuals and groups to live peacefully in a diverse society

\section{Needs of Multicultural Education}

Multicultural Education means different things to different people race, ethnic, structure, language, gender, age, disability, social class education, religious orientation and dimension of other culture are addressed and respected (Gay, 1994). Needs of multicultural education is necessities in educational curriculum. The needs of multicultural educations are described as follows:

\section{Developing Ethnic and Cultural Literacy}

In Nepal, multilingual curriculum provision has mentioned in basic education but in poor in practices. In few number of ethnicity has practiced teaching medium of instruction is as a mother tongue but it isn't effective and efficient due to lack of theoretical and philosophical framework. In the field of multicultural education it is isolated part in the mission and programs of nations(Tatto,2006). Culture has a powerful influence on student's learning. The learning and achievement of self-concept affects the system of beliefs, values, attitudes, social relations, the language, expectations, which they used and the other person's behavior becomes effective through the culture and identity of each individual (Tilaar,2004). Students learn about their own and other's languages, cultural characteristics, critical events, significant individuals, historical backgrounds, majority and minority ethnic groups (Salgur, 2015). Nepal has ethnic diversity, culture and religion since the distant past. Ethnic, cultural, religious diversity are characteristics of the society. Diversity has become the cornerstone of the unity of the people. In other words, diversity should be seen as an opportunity, not a threat. Multi ethnic, multilingual, multi religious people's deep brotherhoods are the reality of the Nepalese people. According to Mostafazaseh, Keshtiaray, \& Ghulizadeh, (2015), The countries in the world today has a cultural and ethnic diversity, unified nation, and enjoy the unity of the land, political, and the national identity abound, cultural pluralism in the era of globalization and the transformation of elite political culture in Nepal. Wink, (2005) has suggested that need of ethnic cultures based educational programming for students in order to achieve citizenship, due to the close relatives of the together. 


\section{Respect for Human Beings and Human Dignity}

Ethnic groups and nationalities have cultural differences and their own cultural features without doubt affect on the current study and subsequent success in influencing society. In fact, the membership of a particular ethnic culture, in determining social status, the role of a person, takes over the duties, privileges granted to them (Mostafazaseh, Keshtiaray, \& Ghulizadeh, 2015) to gain an understanding of themselves and others, motivational study finds that even the perception that the world is influenced on culture that we live in a time determined by the type of culture that we belong to it, in the future we are effective. Culture in its broadest meaning is, knowledge, belief, art, morals, customs and language, in a word, the whole of human social life, etc. as the biology and life for all people, respect, diversity of social needs of the modern world is also endorsed the Declaration of the World (ibid). Education is a cultural activity that explains in terms of cultural scenarios and general knowledge about events that exist in the minds of their creators.

\section{Globalization of Education as Skill Development}

Multicultural education is the one of the wings of globalization, integration of economies and societies through cross country flows of information, ideas, technologies, goods, services, capital, finance and people. It helps to communicate through global adjustment. Cultural experiences and adjustment is must due to rise of cross border trade and the modern global economy. Globalization present the quantity and quality of existing education and training in a country it helps to determine the extent to which a country is likely to be involved in globalization (Sleeter,1996).Education is part of the equation when understanding the dynamics of "brain drain", "brain gain" and "brain circulation". Thus, education and training levels are important factors in both the importation of employment and its exportation.

Now multicultural knowledge is needed not only for doing business with people from other countries, but also growing diversity among those in our own offices. We work next to people of different religions and nationalities who think and act differently than we do. In certain cultures, time is not as important as relationships. So, business deals may take longer so that trust can be built up. We have to understand around different holidays that many may not believe the same you do or celebrate that holiday. Being able to recognize and address these differences help to build stronger teams and better companies.

When companies work together despite differences, unique ideas can turn into success for the company, especially in an area that others might not understand, for example, a country that has a different majority religion. But if we don't learn how to communicate and respect others we will lose valuable opportunities.

One of the significant impacts of contemporary developments in the areas of economic, social and cultural rights, and put in place, this issue, is globalization. Globalization in various aspects of education is faced with serious challenges and changes, so that today the goals, contents, methods and types of educational relations are affected by this phenomenon and it has been inevitable. The relationship between educational systems and curriculum development specialists in different countries, different approaches have been taken to develop its curriculum content. In order to preserve their traditional values and characteristics of the process of globalization has benefited from this state. It has been proven that the educational system needs to have a dynamic, efficient and of course comply with the new requirements needed today more than ever has a culture-centered attitude to globalization. According to Chan, A. (2011) globalization 
processes also increased the movement of people across national boundaries and put phenomena of cultural pluralism in the forefront of political and social issues. Therefore, integration to model of multiculturalism and respect for minority rights is an issue which is in recent years in Western societies and political literature widely discussed and criticized (ibid).Iran's educational system synchronous with other educational systems in the world are exposed to the globalization process and hence should try to use the opportunities that globalization offers the educational community, and measures to reduce the negative effects of its scrap.

\section{New Skill, Knowledge and Training for Teachers}

Teachers are main agent in promoting quality education. Well trained, highly motivated, dedicated and professionally competent teachers are very important. This is strongly related to reward they get from their profession as teachers. Having enough number of teachers in school and class doesn't mean for quality of education but enough number of good quality teachers which are highly motivated and dedicated to their jobs. Multicultural education refers to the learning of appropriate knowledge, attitudes and skills related to the respect and appreciation of different cultures and other differences which include race, ethnicity, religion etc. According to Gollnick and Chinn (1990) has emphasized issues beyond the boundaries of ethnic or racial issues and recommend five goals for multicultural education They include:

the promotion of strength and value of cultural diversity,

an emphasis on human rights and respect for those who are different from oneself,

the acceptance of alternative life choices for people,

the promotion of social justice and equality for all people,

an emphasis on equal distribution of power and income among groups.

Most large societies often have subcultures or groups of people with distinct sets of behavior and beliefs that differentiate them from a larger culture of which they are a part. The subculture may be different because of the age of its members, their race, ethnicity, or class. The qualities that determine a subculture as distinct may be aesthetic, religious, occupational, political, and sexual or a combination of these factors (Bank, 2003). The world becoming a borderless village, increasing interdependence among countries, and the ominous threat of a "clash of civilizations" the issue of multiculturalism and its place in education is becoming more important. A deliberate and conscious effort has to be undertaken to promote respect and not just mere tolerance for differences, including cultural ones which make up the most contentious of differences amongst mankind. This imperative was officially declared even as early as the Swann Report (Huang, H. J. 2002). which emphasized the need to teach all young people how to respect ethnic and cultural differences and to accept them as part of the cultural richness of life in our modern world, and not as a threat. According to Nieto (2000) definition states that "culture consists of the values, traditions, social and political relationships, and world view created, shared, and transformed by a group of people bound together by a combination of factors that can include a common history, geographic location, language, social class, and religion." The teacher who uses the terms and components of students' culture can help them to learn easily and effectively. An equipped teacher who styles his / her own student's behavior and understands well enough the components of culture can follow a path more patiently. Boldley(1994) mentions that culture styles the students' personal development and relations among people's opinions, behaviors, productions and values, assumptions, and perceptions in society. 
Every society has a common culture, each individual has his / her own cultural values. It is important for the students to know and be aware of their cultural importance. Respecting others' cultures and understanding them, and taking care of social cultures is linked with knowing their own cultures

\section{Multicultural Education from Scientific Perspective}

The impact of culture and native language as one of the distinctive aspects of culture-on child is natural and makes his own perception of the world. Gorski, (2005) believes that the culture and language of each child is caused special perception in him and this perception, in turn, led to the emergence of different patterns of thinking, different learning styles and differences in people's behavior. Therefore, the success or failure of each student, over that aspect of a person, goes back to his particular language and culture. Many experts have considered training as a field advantage which has been formed in the social and cultural context of society and impact mutually on it Wilson (2008).Vigotsky also admits, there are always aspects of cultural, historical and social development are very important and he believes the origin of the human psyche, society, According to Sleeter (1996) multicultural education is a fundamental solution to eliminate gaps and preparation of various racial and ethnic groups to live in a democratic society, Students need to know that there are different cultures and different ethnicities how the economic, political and social foundations have role in society and contribute to their personal life. Multicultural education, as developing ethnic and cultural literacy, personal development, attitudes and value clarification, multicultural social, competence.

Students learn about their own and other's languages, cultural characteristics, critical events, significant individuals, historical backgrounds, majority and minority ethnic groups (Salgur, 2015). Nepal has ethnic diversity, culture and religion since the distant past. Ethnic, cultural, religious diversity are characteristics of the society. Diversity has become the cornerstone of the unity of the people so individual will be motivated to learn diversity and their indigenous knowledge. They love their culture and traditions and like to know, preserve and protect. In other words, diversity should be seen as an opportunity, not a threat. 125 caste 123 language various religious peoples' deep brotherhood are the reality of the Nepalese people According to (Mostafazaseh, Keshtiaray, \& Ghulizadeh, 2015), the countries in the world today has a cultural and ethnic diversity, unified nation, and enjoy the unity of the land, political, and the national identity abound, cultural pluralism in the era of globalization and the transformation of elite political culture in Nepal. Tilaar, (2004) state "place of folklore in citizenship education" has suggested that need of ethnic cultures based educational programming for students in order to achieve citizenship, due to the close relatives of the together.

\section{Conclusion}

Nowadays, people are not limited in a certain territory thus the mix societies are increasing. The numerous multicultural environments bring positive and negative effect. Moreover, every culture's multicultural structure is changing day by day. For example, due to various reasons, nowadays, living in a foreign country as a stranger and living together with foreigners is something that occurs quite frequently. Communication is compulsory in living together with different cultures. The multicultural concept or approach may boost the development of new opportunities for sharing each individual's values and for understanding each other in a society. This concept is the most applicable way to overcome the problems of globalization and the complexity of societies all over the world. 
Exploring the dimensions of Multicultural Education and Its Implication in Teaching ... / 41

The people living in a multicultural environment have to interact with the 'others' who may be from different ethnicities, linguistics, religions and cultural backgrounds. In such an environment, there should be no assimilation, exclusion or fusion but rather communication, tolerance, dialogue and interaction. In this case, the roles, aspects and limits of individuals (in such a society) become clearer and fairer. Only multicultural education can overcome all these needs. Because of the constantly changing world, reforms that will fulfill these needs in education are necessary.

The societies are being multicultural due to migration in search of better and comfortable life. This multicultural environment has positive and negative results. Dialogues and communication are compulsory in living together with different cultures. The multicultural approach may boost the development of new opportunities for sharing each individual's values and for understanding each other in a society (Salgur, 2015). This approach is helpful to overcome the problems of globalization and the complexity of societies all over the world. The people living in a multicultural environment have to interact with 'others' who may be from different ethnicities, linguistics, religions and cultural backgrounds. According to (Banks, 2008)dimensions of multicultural education is used widely by school districts to conceptualize and develop courses, programs, and projects in multicultural education. He present the dimensions of multicultural education are content integration, knowledge construction, prejudice reduction, equity pedagogy, an empowering school culture.

These dimensions are applicable in the daily life for individual especially who have involved in academic background. Multicultural education to be very strategic must be able to acknowledge and respect society and manage the plurality creatively. The education in the era of the economic community must understand the national and global issues such as cultural diversity, political, economic, social, conflict and peace, interdependence among nations in the world, human rights, environmental issues such as environmental degradation, disease and migration of the population and so forth.

\section{References}

Banks, J. A. (1999). An introduction to multicultural education. Boston: Allyn and Bacon

Banks, J. A. (Ed.). (2003). Diversity and citizenship education: Global perspectives. San Francisco: Jossey-Bass

Banks, J. A. (2008). Introduction to Multicultural Education. Boston Newwork: Pearson

Boldley, J. H.,(1994).Cultural Anthropology: Tribes, states and global system. New York: Academic Press,

Bruch,P.L.Jehangir,R.R.,Jacobs,W.R.,Ghere,D.L.(2004).EnablingAccess: Towards Multicultural Development Curricula. Journal of Development Education,27(12-18)

Chan, A. (2011). Critical multiculturalism: Supporting early childhood teachers to work with diverse immigrant families. International Research in Early Childhood Education Journal (Online), 2(1), 63.

Central Bureau of Statistics.(2011). Population monograph 2014. Government of Nepal: Central Bureau of Statistics CBS

Gorski, P. C. (2005). Multicultural Education and the Internet (2nd ed.). New York: McGrawHill Higher Education. Education, Inc. 
Gollnick, D., \& Chinn, P. (1990).Multicultural Education in a Pluralistic Society (3rd ed.). New York: Macmillan.

Mostafazadeh, E, Keshtiaray, N. \& Ghulizadeh, A. ( 2015). Analysis of Multi Cultural Education Concept in Order to Explain Its Components. Journal of Education and Practice www. iiste.org .

Huang, H. J. (2002). Designing multicultural lesson plans. Multicultural Perspectives, 4(4), 17 23.

Ministry of Law, Justice and Parliamentary Affairs of Nepal,(2015).Constitution of Nepal 2015.

Mostafazadeh, E, Keshtiaray, N. \& Ghulizadeh, A. ( 2015). Analysis of Multi Cultural Education Concept in Order to Explain Its Components. Journal of Education and Practice www. iiste.org .

Nieto, S. (2000), Affirming diversity: The Socio-Political Context of Multicultural Education. (3rd ed.). New York, NY: Longman,

Patrick L. Bruch, Rashné R. Jehangir, Walter R. Jacobs, David L. Ghere. (2004). Enabling Access: Toward Multicultural Developmental Curricula. Journal of Developmental Education .

Rashné, R., Walter, R. David, Ghere, L. (2004).Enabling Access: Toward Multicultural Developmental Curricula. Journal of Developmental education Vol. 27 P.12

Salgur, S. A. \& Gursay, A. (2015). 'Multicultural Education and Teachers Characteristics. Euromentor Journal , 7-17.

Sleeter, C. E. (1996).Multicultural education as social activism. Albany: State University of New York Press

Tatto, M. T. (2006). Education Reform and The Global Regulation of Teachers' Education, Development, and Work: A Cross-Cultural Analysis. International Journal of Educational Research, 45(4-5), 231-241. https://doi.org/10.1016/j.ijer.2007.02.003

Tiedt, P., \&Tiedt, I. M. (1995).Multicultural teaching: A handbook of activities, information, and resources. Boston: Allyn and Bacon.

Tilaar, H. (2004). Multiculturalism; Global Challenges in Transforming the Future of Education. Jakarta: Grasindo. Torres, C. A. (2002). Globalization, Education, and Citizenship: Solidarity versus Markets. American Educational Research Journal, 39(2), 363-378. https://doi.org/10.3102/00028312039002363

Wilson, K. (2008). What is multicultural education. Retrieved from http://www.edchange.org/ multicultural/ papers/keith.html

Wink, J. (2005).Critical pedagogy: Notes from the real world. Boston, MA: Pearson Education, Inc. 